\title{
BMJ Open What is a medical decision? A taxonomy based on physician statements in hospital encounters: a qualitative study
}

\author{
Eirik H Ofstad, ${ }^{1}$ Jan C Frich, ${ }^{2}$ Edvin Schei, ${ }^{3}$ Richard M Frankel, ${ }^{4}$ Pål Gulbrandsen ${ }^{5}$
}

To cite: Ofstad EH, Frich JC, Schei $\mathrm{E}$, et al. What is a medical decision? A taxonomy based on physician statements in hospital encounters: a qualitative study. BMJ Open 2016;6:e10098. doi:10.1136/bmjopen-2015010098

- Prepublication history and additional material is available. To view please visit the journal (http://dx.doi.org/ 10.1136/bmjopen-2015010098)

Received 24 September 2015 Revised 4 January 2016 Accepted 18 January 2016

CrossMark

For numbered affiliations see end of article.

Correspondence to

Dr Eirik H Ofstad;

eirikofstad@gmail.com

\section{ABSTRACT}

Objective: The medical literature lacks a comprehensive taxonomy of decisions made by physicians in medical encounters. Such a taxonomy might be useful in understanding the physician-centred, patient-centred and shared decision-making in clinical settings. We aimed to identify and classify all decisions emerging in conversations between patients and physicians.

Design: Qualitative study of video recorded patientphysician encounters.

Participants and setting: 380 patients in consultations with 59 physicians from 17 clinical specialties and three different settings (emergency room, ward round, outpatient clinic) in a Norwegian teaching hospital. A randomised sample of 30 encounters from internal medicine was used to identify and classify decisions, a maximum variation sample of 20 encounters was used for reliability assessments, and the remaining encounters were analysed to test for applicability across specialties.

Results: On the basis of physician statements in our material, we developed a taxonomy of clinical decisions - the Decision Identification and Classification Taxonomy for Use in Medicine (DICTUM). We categorised decisions into 10 mutually exclusive categories: gathering additional information, evaluating test results, defining problem, drug-related, therapeutic procedure-related, legal and insurance-related, contactrelated, advice and precaution, treatment goal, and deferment. Four-coder inter-rater reliability using Krippendorff's $\alpha$ was 0.79 .

Conclusions: DICTUM represents a precise, detailed and comprehensive taxonomy of medical decisions communicated within patient-physician encounters. Compared to previous normative frameworks, the taxonomy is descriptive, substantially broader and offers new categories to the variety of clinical decisions. The taxonomy could prove helpful in studies on the quality of medical work, use of time and resources, and understanding of why, when and how patients are or are not involved in decisions.

\section{INTRODUCTION}

Decision-making is a key activity in patientphysician encounters, with decisions as the

\section{Strengths and limitations of this study}

A taxonomy was developed through a contentdriven iterative process using qualitative methods.

- The taxonomy was tested on video recorded patient-physician encounters comprising 17 different clinical specialties, three practice settings (outpatients, inpatients on the ward, emergency room) and several hundred cases.

- The encounters were recorded at a single hospital, and the taxonomy has not been tested in general practice or psychiatry.

outcomes of such activity. ${ }^{1}$ Decision-making can be regarded as the cognitive process resulting in the selection of a belief or a course of action among several alternative possibilities. $^{2}$

The words decision and judgement are used as synonyms in everyday and medical language, ${ }^{3}$ which is reflected in the research and theory on clinical judgement and decision-making that have advanced healthcare in the past five decades. ${ }^{1}{ }^{4-9}$ Medical decision science has descriptive, normative and prescriptive functions: explaining how patients and physicians routinely make decisions, proposing standards for ideal decisionmaking, and providing tools to make good decisions in practice, respectively. ${ }^{1}$ Attempts to define decisions have followed these function-specific patterns. For example, Sackett et $a l^{10}$ define evidence-based decisions as 'the integration of best research evidence with clinical expertise and patient values'. Haynes et $a l^{11}$ have pointed out that this is a prescriptive rather than descriptive approach to medical decisions: 'It is a guide for thinking about how decisions should be made rather than a schema for how they are made'.

Clinical encounters often deal with multiple problems, with several decisions being made. In a study of patient involvement in 
decisions, Braddock et $a l^{12}$ developed a descriptive definition of a medical decision as 'a verbal statement committing to a particular course of action'. This definition is broad and includes actions leading to diagnostic tests, prescriptions, referrals and instructions regarding diet and physical activity. However, it does not capture decisions that influence the subsequent 'courses of action', such as evaluations of findings and tests, and interpretations concerning diagnosis, prognosis and aetiology, most likely because patient involvement in such decisions is not considered relevant.

Deber ${ }^{13}$ made a distinction between 'problem-solving', which was defined as the 'search for a single correct solution to a problem, and 'decision-making', which was defined as 'situations in which a choice must be made among one of several alternatives'. However, medical 'problem-solving' often involves 'decision-making' on the path to a conclusion, best illustrated by the fact that diagnostic conclusions seldom reveal themselves; they have to be produced by someone. ${ }^{14}$ Most of the time, diagnostic problem-solving and therapeutic actions present options that require decision-making and leave room for interpretation because of medical and contextual complexity. ${ }^{15}$

The literature lacks a comprehensive system for classifying medical decisions in patient-physician encounters. In order to better understand clinical decision-making processes, we aimed to identify and classify all decisions emerging in conversations between patients and

\begin{tabular}{lrc} 
Table 1 Characteristics of the physicians, patients and \\
encounters in our sample & N & Per cent \\
\hline \multicolumn{2}{l}{ Nents } & 380 \\
\hline Patients & 186 & 49 \\
Men & 194 & 51 \\
Women & 82 & 22 \\
Age 0-17 (years) & 174 & 46 \\
Age 18-60 & 124 & 32 \\
Age >60 & 59 & \\
Physicians & 35 & 59 \\
Men & 24 & 41 \\
Women & 31 & 53 \\
Age <40 (years) & 28 & 47 \\
Age $\geq 40$ & 380 & \\
Encounters by specialty & 130 & 34 \\
Internal medicine* & 106 & 28 \\
Surgical disciplines $\dagger$ & 55 & 15 \\
Paediatrics & 54 & 14 \\
Neurology & 35 & 9 \\
Obstetrics and gynaecology & 380 & \\
Encounters by setting & 291 & 77 \\
Outpatient clinic & 58 & 15 \\
Ward round & 31 & 8 \\
Emergency room &
\end{tabular}

${ }^{*}$ Cardiology, respiratory medicine, nephrology, gastroenterology, endocrinology, haematology, infectious diseases and oncology. †Gastro surgery, urology, thorax \& vascular surgery, orthopaedics, ear-nose-throat, anaesthesiology. physicians. This paper describes the process from initial observations of video recorded patient-physician encounters, through deliberations about what constitutes a decision, to the development of a taxonomy of decisions. Such a taxonomy could be helpful in teaching, and in studies on quality of medical work, its financial implications, understanding of patient involvement, and disentangling the complexity of physicians' everyday tasks.

\section{METHOD}

We conducted a qualitative study where we studied video recorded patient-physician encounters in a hospital setting.

\section{Material}

Available for our study by broad consent were 380 video recorded physician-patient encounters collected at a large Norwegian teaching hospital (Akershus University Hospital) in 2007-2008, as a part of a randomised controlled trial, to evaluate the effect of a $20 \mathrm{~h}$ communication skills course. ${ }^{16}$ While $55 \%$ of the videos were recorded before communication training, $45 \%$ were recorded after training. The physicians were randomly drawn from all physicians under 60 years of age working in clinical departments; 71 of 103 (69\%) invited physicians consented to participate in the trial, and 59 provided broad consent. Patients were recruited consecutively on the days the participating physicians were available, and $94 \%$ agreed to have their encounter videotaped. ${ }^{17}$ The distribution of patients, physicians and encounters is shown in table 1 . The average duration of the encounters was $22 \mathrm{~min}$.

\section{Method}

We assembled a team of physicians to analyse the videotaped encounters starting autumn 2010. The fourmember project team consisted of a specialist registrar in internal medicine/research fellow (EHO), a neurologist/professor (JCF), a general practitioner/professor (ES) and a professor of health services research/previously a general practitioner and a public health specialist (PG). Informed by previous medical training, we had no problem with understanding the words and actions observed in the encounters. The team had a continuous dialogue about the potential biases generated by a shared medical perspective. To contrast the medical perspective, we included a social psychologist/communication specialist (RMF) in the analytic phase of the study.

We started from the top of a randomised list of the 380 videos to get an overall impression, and studied encounters without any particular coding structure in mind. We aimed to describe what the content and constituent elements of clinically relevant decisions were and when clinical decisions were made. This process is identical with what Borkan, Miller and Crabtree describe as immersion/crystallisation, ${ }^{18}$ except that our study was informed by previous work. ${ }^{12}$ Trying to structure the 
seemingly natural flow of the encounters, we made SOAP notes ${ }^{19}$ of each encounter. SOAP notes structure medical encounters into a subjective (patient history), objective (clinical examination), assessment (diagnosis) and planning phase. These notes provided a useful tool in the analysis. The group reflected on events that suggested that decisions were being made, and we had extensive discussions about the threshold for claiming that an observed statement or action signified a decision. We agreed that all statements had to include some element of medically relevant content in order to count as a medical decision, for example, 'We have to operate on you' was included by such a requirement, while 'We'll order a train ticket for you to get home' was not. We also agreed that all statements needed to be related to the actual patient's concrete situation and be distinct from general medical information in order to count as a medical decision, for example, 'I think you got lung cancer due to smoking' was included by such a requirement, while 'Smoking is the most common cause for lung cancer' was not.

We developed the following definition of a medical decision: 'A verbal statement committing to a particular course of clinically relevant action and/or statement concerning the patient's health that carries meaning and weight because it is said by a medical expert'. Details about the development of the definition and the temporal characteristics of decisions are described in a previously published paper. ${ }^{20}$

Being able to identify decisions, we proceeded with attempts to categorise them. Transcriptions of all statements conveying decisions from the first 30 encounters were gathered and sorted according to categories that were given provisional names, a process described by Addison, Miller and Crabtree as an editing style of analysis. ${ }^{21}$ This process was partly inductive, establishing new categories, and partly deductive, building on categories that might be labelled as self-evident, that is, prescription of drugs, ordering a diagnostic test, etc-categories comprised by Braddock et als ${ }^{12}{ }^{22}$ studies. The main criteria for establishing and maintaining categories were that they captured relevant decisions and that a category was mutually exclusive from other categories. The unit of analysis was statements that conveyed medical decisions. This iterative process resulted in a coding scheme with 10 topical categories. We now saw the contours of a taxonomy. ${ }^{23}$

We tested the categories on new recordings in order to examine the taxonomy's applicability and to evaluate interoperator variability. We selected samples of five videos from different settings and specialties in order to ensure a maximum variation. ${ }^{24}$ All four physicians coded the five videos according to the current version of the taxonomy. This process was repeated three times with new videos. The taxonomy underwent revision twice, leading to two modifications of the categories (combining referrals with other contact-related decisions and distinguishing evaluating test results from defining problem decisions, respectively). This process is described by Miller and Crabtree as template analysis. ${ }^{25}$ By the end of 2011, we reached consensus on a version of the taxonomy that we deemed fit for reliability testing. We used Krippendorff's $\alpha$-agreement for content coding, ${ }^{26}$ which allows for the comparison of many coders, many nominal categories and missing values. We coded a final set of five new videos to assess reliability with Krippendorff's $\alpha$. A total of 20 videos were used for these four rounds of consistency and reliability assessments. The remaining 330 encounters were analysed to test the taxonomy's applicability in other specialties.

\section{RESULTS}

Our methodological approach yielded a taxonomy comprising 10 categories (table 2). The taxonomy was named the Decision Identification and Classification Taxonomy for Use in Medicine (DICTUM; see online supplementary 1). We describe below the characteristics of each category and the function it performs in medical encounters using quotes from the 380 videos in our corpus, as shown in table 3 . The categories are ordered starting with diagnostic, followed by therapeutic and ending with consulting and decisions about management. The quotes are verbatim extracts from the dialogue and are presented with contextual information including setting, specialty and clinically relevant problem/diagnosis. Since the videos were recorded 7 years ago, some of the recommendations and therapeutic regimens touched on in the selected transcriptions may have changed and may not reflect current practice.

\section{Category \#1: gathering additional information}

This category describes decisions to obtain information from other sources than patient interview, physical examination and patient chart.

In the clinical encounter, a physician gathers information through the patient interview, physical examination and chart review. The taxonomy does not define these actions as clinically relevant decisions. However, when a physician explicitly demonstrates gathering additional information, that is, ordering a diagnostic test, calling a colleague to discuss the patient's problem, seeking external information from other parties (general practitioner, family member, other hospital, etc.), such actions are coded as decisions. This category generally functions to increase the amount and precision of information related to the patient's problem, previous history or context-either because the information cannot be provided by the patient, because the physician does not feel competent or certain enough to decide alone, or because the patient's problem requires additional diagnostic information gained by tests.

\section{Category \#2: evaluating test result}

This category describes simple, normative assessments of clinical findings and tests and why they in the taxonomy are defined as clinically relevant decisions. 
Table 2 The Decision Identification and Classification Taxonomy for Use in Medicine (DICTUM)

\begin{tabular}{|c|c|c|c|}
\hline \multicolumn{2}{|c|}{ Category name } & \multirow{2}{*}{$\begin{array}{l}\text { Category description } \\
\text { Decision to obtain information from other source than } \\
\text { patient interview, physical examination and patient } \\
\text { chart }\end{array}$} & \multirow{2}{*}{$\begin{array}{l}\text { Subcategory } \\
\text { Ordering test, consulting colleague, } \\
\text { seeking external information }\end{array}$} \\
\hline 1 & $\begin{array}{l}\text { Gathering } \\
\text { additional } \\
\text { information }\end{array}$ & & \\
\hline 2 & $\begin{array}{l}\text { Evaluating test } \\
\text { result }\end{array}$ & $\begin{array}{l}\text { Simple, normative assessments of clinical findings } \\
\text { and tests }\end{array}$ & Positive, negative, ambiguous \\
\hline 3 & Defining problem & $\begin{array}{l}\text { Complex, interpretative assessments that define what } \\
\text { the problem is and reflect a medically informed } \\
\text { conclusion }\end{array}$ & $\begin{array}{l}\text { Diagnostic conclusion, evaluation of health } \\
\text { state, aetiological inference, prognostic } \\
\text { judgement }\end{array}$ \\
\hline 4 & Drug related & $\begin{array}{l}\text { Decision to start, refrain from, stop, alter or maintain a } \\
\text { drug regimen }\end{array}$ & Start, stop, alter, maintain, refrain \\
\hline 5 & $\begin{array}{l}\text { Therapeutic } \\
\text { procedure related }\end{array}$ & $\begin{array}{l}\text { Decision to intervene on a medical problem, plan, } \\
\text { perform or refrain from therapeutic procedures of a } \\
\text { medical nature }\end{array}$ & Start, stop, alter, maintain, refrain \\
\hline 6 & $\begin{array}{l}\text { Legal and } \\
\text { insurance related }\end{array}$ & $\begin{array}{l}\text { Medical decision concerning the patient, which is } \\
\text { based on or restricted by legal regulations or financial } \\
\text { arrangements }\end{array}$ & $\begin{array}{l}\text { Sick leave, drug refund, insurance, } \\
\text { disability }\end{array}$ \\
\hline 7 & Contact related & $\begin{array}{l}\text { Decision regarding admittance or discharge from } \\
\text { hospital, scheduling of control and referral to other } \\
\text { parts of the healthcare system }\end{array}$ & Admit, discharge, follow-up, referral \\
\hline 8 & $\begin{array}{l}\text { Advice and } \\
\text { precaution }\end{array}$ & $\begin{array}{l}\text { Decision to give the patient advice or precaution, } \\
\text { thereby transferring responsibility for action from the } \\
\text { provider to the patient }\end{array}$ & Advice, precaution \\
\hline 9 & Treatment goal & $\begin{array}{l}\text { Decision to set defined goal for treatment and thereby } \\
\text { being more specific than giving advice }\end{array}$ & Quantitative, qualitative \\
\hline 10 & Deferment & $\begin{array}{l}\text { Decision to actively delay decision or a rejection to } \\
\text { decide on a problem presented by a patient }\end{array}$ & $\begin{array}{l}\text { Transfer responsibility, wait and see, } \\
\text { change subject }\end{array}$ \\
\hline
\end{tabular}

The objective phase of a SOAP-modelled encounter ${ }^{19}$ is where the physician gathers information through physical examination. A clinical examination is the execution of idealised tests normatively assessing bodily functions. The way the clinician assesses these and other tests, such as lab results and X-ray images, may be referred to as clinical judgement. ${ }^{4}$ Even though tests generally are appended with standardised interpretations of normality and pathology, the clinician has to decide whether or not this test result matters and how it influences the specific context. The clinician also needs to take the test's likelihood of being true or false into account by interpreting the test in the light of its sensitivity and specificity. ${ }^{6}$

A blood pressure of $140 / 80 \mathrm{~mm} \mathrm{Hg}$ could be described as too high in a teenager, while it might be ideal for a 90-year-old without known vascular disease or a 50-year-old with severe treatment-resistant hypertension. Like other tests, a blood pressure measurement does not speak for itself; somebody has to decide how to interpret it in a specific context. ${ }^{14}$ In the taxonomy, normative assessments of diagnostic tests are defined as decisions while simple assessments of the patient's history without further elaboration are not. The function of this category is to separate normal from pathological processes and to create building blocks for more complex assessments such as diagnoses and prognoses.

\section{Category \#3: defining problem}

This category describes complex, interpretative assessments that define what the problem is and reflects a medically informed conclusion.

In the assessment phase of the SOAP-modelled encounter, the physician interprets the patient's history, clinical findings and diagnostic tests using clinical reasoning to understand the patient's problem(s). These complex, interpretative statements differ from simple, normative statements in the way that they serve at least one of four functions: diagnostic conclusion, evaluation of state of health, aetiological inference or prognostic judgement.

This category has two main functions. First, to categorise any conglomerate of symptoms, signs, findings and beliefs into a biomedical framework of understanding, namely the taxonomy of diagnoses. We observed that these decisions occasionally yielded a first-time diagnosis, but more often decisions were made to rule out a disease, or an assessment of the patient's health state in the context of a known disease. Along with diagnoses follows the possibility of prognostic judgements and aetiological inferences. Statements reflecting such decisions have the potential to establish order and predictability in complex and often emergent situations, thereby informing both the patient and providers about the what, how and when of the given problem. Second, these decisions set the stage for prescriptive measures, 
Table 3 Transcribed examples of statements conveying decisions according to DICTUM

\section{Category subgroup Physician statement}

1 Order test

$$
\text { 'I'll get an ultrasound of it tonight' }
$$

'There is no point in a new EEG now'

'You'll send in faecal tests after four, six and 8 weeks...'

'We'll do the A1c and some blood tests afterwards'

Consulting colleague 'This is a bit special so I will discuss it with a colleague'

'I will discuss it a bit with my consultant'

External information 'We will get those images sent over and have them assessed'

2 Good

' $140 / 80 \ldots$ I think that is very good'

'I see that your A1c is 8.1 , that is great'

'The X-ray looks fine'

'Everything was in perfect order; I found nothing wrong' (after full neurological examination)

$\mathrm{Bad}$

'Your A1c was not so good'

'You are a bit low on potassium'

'Your blood pressure is high. $180 / 100$ is high'

Ambiguous

3 Diagnosis

'It wasn't too bad, but it's not great either' (after lung auscultation)

'This is a classic case of light asthma'

'Ganglion [cyst] it is called'

'Based on today's examination I think it is more likely that you've had a minor stroke' 'This is basically what we call osteoarthritis'

Aetiology

'I think it is paracetamol and dextropropoxyphen that has damaged your liver'

'It is the torn cruciate ligament that prevents your knee from stopping where it should'

Prognosis

Evaluating state of health

4 Start

'The chemotherapy cannot remove what you have on your lungs'

'You can profit on training up to a year after the injury'

'Your diabetes is very well regulated'

'He's breathing nice and slowly, I think he has responded well to treatment'

'We'll start with azathioprine 50 mg'

'I was thinking you should get desloratadine, allergy pills'

'We'll give a 4-day treatment of dexamethasone'

'I would like you to get some vaginal oestrogen'

Refrain

'We cannot give you chemo today'

'You should not take ibuprofene or other blood thinners before the surgery'

Stop

'It means that you can stop taking $\beta$-blockers'

'You should cut the iron tablets'

'You'd better reduce to 50 [micrograms of levothyroxine]'

Alter

'Go down to two plus two [prednisolone $5 \mathrm{mg}$ ]"

'You should increase the insulin detemir dosage 2 units at a time'

\section{Context}

ER, internal medicine, deep vein thrombosis?

OPC, neurologist, epilepsy

OPC, gastroenterology, Crohn's disease

OPC, endocrinology, type 2 diabetes

OPC, gastroenterology, Crohn's disease

IPW, nephrology, respiratory infection?

OPC, urology, kidney tumour

OPC, nephrology, chronic kidney disease

OPC, endocrinology, type 2 diabetes

OPC, orthopaedics, hip replacement FU

OPC, neurology, headache

OPC, endocrinology, type 2 diabetes

IPW, infectious disease, erysipelas

OPC, cardiology, thoracic aorta graft FU

IPW, infectious disease, pneumonia

OPC, infectious disease, sinusitis and

dyspnoea

OPC, orthopaedics, lump on wrist

IPW, neurology, left side paresis

OPC, orthopaedics, knee pain

IPW, gastroenterology, pneumonia

OPC, orthopaedics, knee pain

OPC, oncology, lung metastases

IPW, neurology, stroke

OPC, endocrinology, type 2 diabetes

IPW, paediatrics, bronchiolitis

OPC, gastroenterology, Crohn's disease

OPC, paediatrics, IBD and seasonal

allergy

IPW, paediatrics, bronchiolitis

OPC, gynaecology, uterine prolapse

OPC, oncology, Gl-cancer, low neutrophil count

IPW, anaesthesiology, preoperative

assessment

OPC, cardiology, tachyarrhythmia

OPC, cardiology, chronic heart failure

OPC, endocrinology, Graves' radio-iodine

FU

OPC, gastroenterology, Crohn's disease OPC, endocrinology, type 2 diabetes 


\section{Category subgroup}

Maintain

$5 \quad$ Surgery

Radiation

Interventional

radiology

Focused care

6 Drug refund

Sick leave

Disability

Admit

Discharge

Telephone

Referral

$8 \quad$ Smoking

Exercise

Diet

Weight

Hydration

Alcohol
7 Schedule

Physician statement

'You should continue taking salbutamol when you need to'

'Cortisone, you'll take as earlier'

'As a foundation you should always take paracetamol $1 \mathrm{~g} 4$ times a day'

'It's alright to get this operated'

'We cannot operate more on you'

'And I will refer you to radiation therapy'

'As long as you are good we are not going to do anything now' (angiography/PCl)

'We'll take off this part of the cast so that you'll be able to bend your finger' 'I think you should go a couple of weeks without the [vaginal] ring'

'You don't have to change on the wound every day, it only irritates, let it be'

'Esomeprazole and pantoprazole are the same, pantoprazole is cheaper and the State has decided that you should drive an Opel, not a BMW'

'Owing to this [muscular stiffness on simvastatin] you qualify for atorvastatin'

'You will get a sick leave note from us'

'We'll keep it like that [50\% absent from work]'

'You will be in paid leave from work for at least 3 months'

'The way you function right now you cannot drive your car'

'I'll schedule a control for you here in 3 months'

'I won't schedule a new control here, seeing that you have a new appointment at the cancer centre'

To patient's mom: 'My suggestion is that he is admitted to the bed ward'

'I think you should spend the night in our observation ward'

'She is so weak that she should be admitted'

'We are going to have to send you home while we wait for an opening [at the nursing home]'

'We thought you were going to get to go home today'
'I'll call you when I get back the results'

'I will refer you to a neurologist'

'I'm thinking I'll send a referral to a physiotherapist'

'I would recommend you to cut it completely'

'It will require effort from you-you will have to stop smoking'

'I would recommend you to increase your level of activity'

'I would stay away from soccer'

'Mind the calories; sweetened beverages, potato chips, cakes, sauces..'

'The weight increase should not continue, then you'll have crossed a line'

To boy's mom: 'He should get at least 3-4 glasses [to drink] per day'

'Be careful to drink a lot of water'

'Together with warfarin, it's not advisable to drink alcohol'
Context

OPC, paediatrics, asthma and allergy

OPC, endocrinology, Addison's disease

OPC, oncology, metastasised GI-cancer

OPC, gastro surgery, haemorrhoids

OPC, orthopaedics, elbow fracture FU

OPC, haematoid-oncology, chemotherapy

OPC, cardiology, coronary artery disease

OPC, orthopaedics, lower arm fracture FU

OPC, gynaecology, uterine prolapse

OPC, gastro surgery, laparotomy FU

OPC, gastro surgery, laparotomy FU

OPC, nephrology, chronic kidney disease

ER, shortness of breath, admittance

OPC, orthopaedics, leg fracture FU

IPW, neurology, stroke

IPW, neurology, stroke

OPC, gastroenterology, Crohn's disease

OPC, haematology-oncology, radiation

OPC, thorax surgery, pneumothorax $E R$, internal medicine, shortness of breath $E R$, paediatrics, vomiting

IPW, cardiology, arrhythmia, not self-sufficient

IPW, cardiology, bleeding ulcer and heart failure

OPC, haematology-oncology,

Waldenstrom's disease?

OPC, oncology, metastasised renal cancer

OPC, gynaecology, uterine prolapsed

OPC, type 2 diabetes, weekend smoker

IPW, cardiology, recent heart attack

OPC, endocrinology, type 2 diabetes

OPC, orthopaedics, ACL rupture pending surgery

OPC, gastro surgery, rectal cancer FU

OPC, nephrology, chronic kidney disease

IPW, paediatrics, gastroenteritis

OPC, gastro surgery, sigmoidostomy

IPW, cardiology, right-sided heart failure 
Table 3 Continued

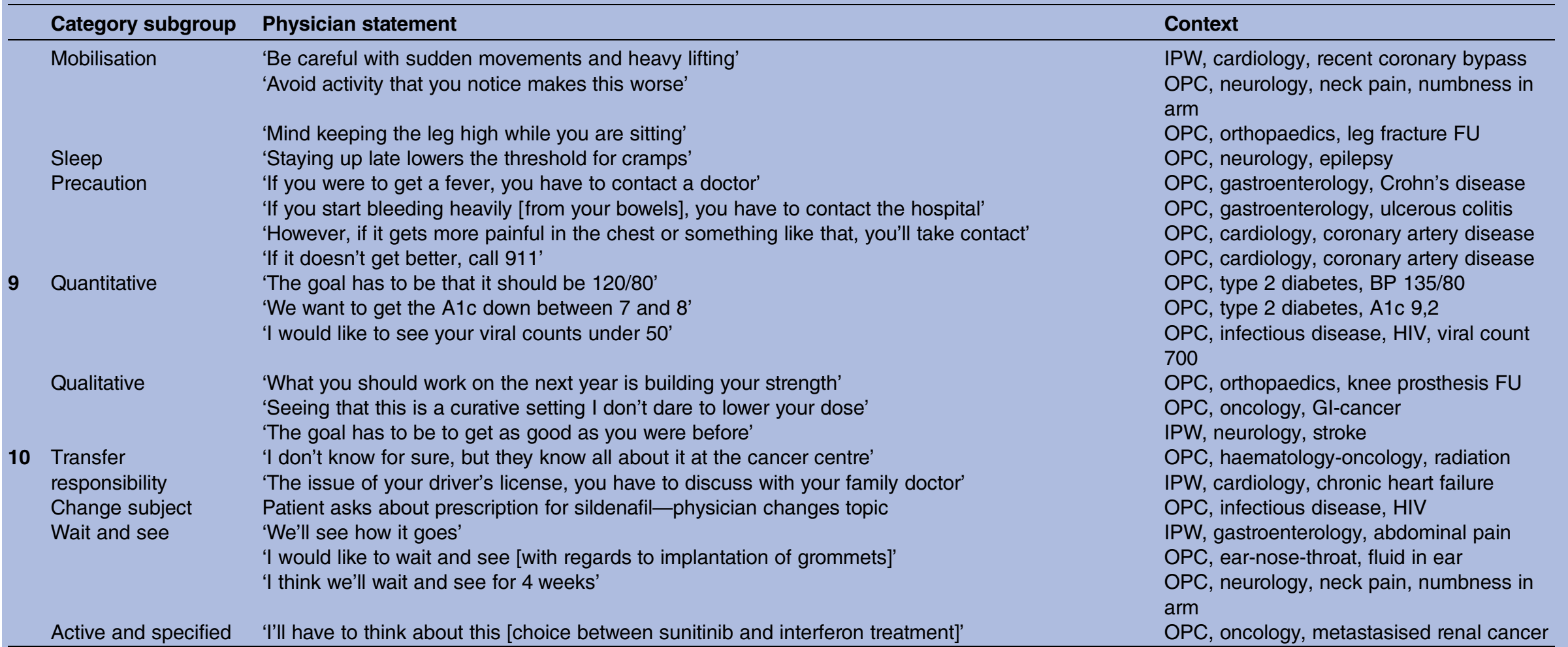
ACL, anterior cruciate ligament; A1c, glycated haemoglobin; BP, blood pressure; ER, emergency room; FU, follow-up; Gl, gastrointestinal; IBD, inflammatory bowel disease; IPW, inpatient ward; OPC, outpatient; PCI, percutaneous coronary intervention. 
like advice on self-management of a problem or biomedical interventions like drugs or surgery.

\section{Category \#4: drug related}

This category describes decisions to start, refrain from, stop, alter or maintain a drug regimen.

In the planning-phase of the SOAP model, the most intuitively clear-cut category involves starting, refraining from, stopping, altering or maintaining a drug regimen. In the taxonomy, any statement committing to drug-related action is defined as a decision, including both prescription and over-the-counter drugs such as vitamin supplements and herbal medicine, including all modes of administration: tablets, suppositories, intravenous, nebulisers, etc. The function of decisions to start, maintain or adjust drug regimens is an intention to improve on and/or prevent a medical problem by transferring professional promise of improvement to a proxy containing chemical substances designed to affect specific systems of human chemistry.

\section{Category \#5: therapeutic procedure related}

This category describes decisions to intervene on a medical problem, plan, perform or refrain from therapeutic procedures of a medical nature.

In addition to pharmaceutical therapy, medicine offers hands-on interventions performed by health professionals to prevent or solve medical problems, for example, surgery, wound care, interventional radiology and radiation therapy. The function of decisions to start or maintain non-pharmaceutical interventions is the intention to improve on and/or prevent a medical problem using hands-on technical craftsmanship, possibly aided by sophisticated technical equipment.

\section{Category \#6: legal and insurance related}

This category describes medical decisions concerning the patient, which is based on or restricted by legal regulations or financial arrangements.

Medical care operates within a legal and political context. Medical encounters contain decisions concerning the patient, which are based on or restricted by legal and financial arrangements. Such decisions might relate to the economic or social benefits the patient is or is not entitled to. The function of legal and insurance-related decisions in clinical encounters is to enforce the framework healthcare provided within when it comes to laws and norms that govern both patients and providers.

\section{Category \#7: contact related}

This category describes decisions regarding admittance or discharge from hospital, scheduling of control and referral to other parts of the healthcare system.

In the planning phase of the SOAP-modelled encounter, plans for future contact with the healthcare system are made. In hospital encounters, these decisions concern being admitted or discharged from the hospital, scheduling of a follow-up appointment or referrals to other parts of the healthcare system. These decisions describe a trajectory of future meetings between a patient and a provider and also implicitly say something about the health condition in question.

\section{Category \#8: advice and precaution}

This category describes decisions to give the patient advice or precaution, thereby transferring responsibility for action from provider to patient.

Just like simple and complex assessments (the 'Evaluating test result' and 'Defining problem' categories), advice carries meaning and weight when stated by a physician in a clinical setting. Advice transfers responsibility for action from provider to patient. In accordance with Braddock et $a l,{ }^{12}$ we defined clinically relevant advice as decisions. Physicians have the option to give advice or not and, if given, options on how to formulate and customise the advice depending on the context.

The main function of giving advice is the intention to affect patient behaviour in a medically favourable direction. A central function of precautionary advice is to provide the patient with useful information on how to act in the face of symptoms. Another function could be a perception that the provider/institution is less accountable for future events following such information.

\section{Category \#9: treatment goal}

This category describes decisions to set defined goals for treatment, thereby being more specific than giving advice.

Regardless of a patient's health condition or disease, physicians define or describe goals and expected outcomes of treatment. In our material, physicians seldom explored patients' goals, but they frequently set targets and goals for patients. These goals might be set using a numerical value, like blood pressure, glycated haemoglobin levels or viral counts. The function of a treatment goal is to define concrete desirable end points of a treatment process using symptom abatement or surrogate markers.

\section{Category \#10: deferment}

This category describes decisions not to make decisions -in other words, to actively delay a decision or a rejection to decide on a problem presented by a patient.

For various reasons, physicians and sometimes patients defer decisions. It might be a decision to actively delay a decision, most often displayed as 'Let's wait and see'. Deferment decisions also comprise transferring the decision-making responsibility to another person or by changing the subject.

The function of deferments is to sort problems in or out of the present context, either by naming another person or place in time as the proper context, or simply by ignoring it (deliberately or inattentively). 
Inter-rater reliability

To assess the reliability of the taxonomy, we did a fourcoder inter-rater-reliability test using Krippendorff's $\alpha$. All four coders coded the same five videos, which returned $\alpha=0.79$. This is virtually the same as Krippendorff's cut-off value of 0.8 needed for coded variables to be reliable. ${ }^{26}$ Average time to code an encounter per physician was 1-1.5 times the visit.

\section{DISCUSSION}

DICTUM is the first comprehensive taxonomy of physician-made medical decisions in patient-physician encounters. The taxonomy provides a precise, detailed and comprehensive description of medical decisions communicated within the patient-physician encounter.

We aimed to identify all observable physician decisions that had relevance to a medical and/or a patient perspective. From a medical point of view, the taxonomy comprises any clinically relevant task that needs to be dealt with in an encounter: from interpreting the patient's story, symptoms, clinical findings and diagnostic tests, to the translation of this knowledge into actions including medical interventions, providing relevant contextualised information to the patient and appropriate level of follow-up.

From the patient's perspective, the statements coded as decisions sum up bullet points of information the patient can take home from the encounter. Imagine a patient coming home to his spouse or parent and being asked; 'So what did the doctor say?' The response could be a summary of the statements identified as decisions by the taxonomy, for example, 'The doctor concluded that I have pneumonia and gave me some antibiotics. She said I will be fine again, but that it could take as long as a month before all symptoms will pass. I have to go back to control my chest X-ray in 6-8 weeks. She said I should stop smoking. When I asked if I could get any of the pills available for smoking cessation, she said I have to speak with my family physician'. This example is probably more structured, detailed and medicocentred than patients' real-life summaries of medical encounters would be, but it is provided to depict the amount and complexity of clinically relevant outcomes that is communicated to patients.

The taxonomy differs from other decision frameworks. Where evidence-based medicine (EBM), shared decisionmaking (SDM) and informed decision-making (IDM) are all normative approaches with prescriptive motives, DICTUM is descriptive. Where EBM and SDM, in general, focus on a single decision, our taxonomy aims to identify all decisions. Some earlier studies aimed to include more than one decision and identified between three and seven decisions per encounter. ${ }^{12} 222^{27-29}$ In these studies, measuring the involvement of patients was the primary aim.

In addition to action statements, the taxonomy includes judgement statements, mainly represented in the two categories 'Evaluating test results' and 'Defining problem'. Ely et $a l^{30}$ developed a taxonomy of clinical questions to assess how physicians deal with the challenges of treatment, choice of tests and also diagnosis, prognosis and aetiology, by building their framework around clinical questions instead of the decisions that produced the answers. ${ }^{31}$ DICTUM also includes decisions leading to actions like ordering a test, selecting level of care and follow-up, or whether a colleague has to be consulted or not. In other recently published studies, all these actions have been referred to as 'key decisions' or 'clinical decisions'. ${ }^{32-35}$

\section{Strengths and limitations}

A strength of DICTUM is that it has been developed and tested on video recorded patient-physician encounters comprising 17 different clinical specialties, three practice settings (outpatients, inpatients on the ward, emergency room) and several hundred cases. Potential limits of this study are that the encounters were recorded in a single hospital and that the taxonomy has not been tested in general practice or psychiatry. The categories are broad, still specific and only rarely have we encountered decisions that challenged the mutual exclusivity of categories. In the few cases where a statement could fit into more than one category, the codebook-developed through a continuous iterative process -provided guidance (see online supplementary for examples). Our Krippendorff's $\alpha$ assessment of interrater reliability was 0.01 below the threshold for coded values to be reliable. We view the composition of our project team as a strength.

\section{Implications}

The taxonomy may be used to create maps and profiles of encounters that could provide useful feedback to physicians. Such encounter maps could also describe similarities and differences between specialties and single physicians, and enlighten understanding of possible differences between encounters with patients based on their age, social status or ethnicity. The taxonomy could also be used as a tool for both physicians and patients to increase awareness of when decisions are made, who makes them and who should make them. Increased awareness could set the stage for dialogue around the level of patient involvement, as well as improve the quality of decision-making processes. Exposing physicians and patients to the taxonomy and observing how they interact afterwards is a possible future approach.

Our contribution pinpoints the difficult task of precisely defining what a decision is, because decisions are distributed over time, space and agents and come in all shapes and colours: from the intuitive one hundredth of a second action to the everlasting deliberation process. Within the boundaries of the patient-physician encounter, our definition and taxonomy adds necessary precision to mapping the decisional terrain. The taxonomy answers where, but not how. Hopefully, a descriptive tool could assist a normative approach in future studies of 
clinical decision-making. Assessment of clinical decisions as such may not have causal effects on performance, but could serve as a first step on the path to increased awareness of what has the potential to improve.

\section{Author affiliations}

${ }^{1}$ The Research Centre, Akershus University Hospital, Lorenskog, Norway

${ }^{2}$ Institute of Health and Society, University of Oslo, Oslo, Norway

${ }^{3}$ Department of Global Public Health and Primary Care, University of Bergen, Bergen, Norway

${ }^{4}$ Indiana University School of Medicine, VA HSR\&D Center of Excellence,

Roudebush VA Medical Center, Indianapolis, Indiana, USA

${ }^{5}$ Institute of Clinical Medicine, Campus Ahus, University of Oslo, Lorenskog, Norway

Twitter Follow Eirik Ofstad at @eirikhugo

Acknowledgements The authors would like to thank Bård Fossli Jensen for recording a vast majority of the videos.

Contributors EHO and PG contributed equally to this study. PG conceived the study and put together the study group. EHO analysed the first 30 videos and selected statements to be discussed in the study group. EHO, JCF, ES and PG took part in all seven group meetings and all four independently analysed the last 20 videos. Owing to the language barrier, RMF did not take part in analysis of the videos, but transcribed and translated statements were presented to RMF during the analytic phase. EHO and PG analysed the remaining 330 videos. EHO, JCF, ES, RMF and PG analysed the data and reviewed the manuscript for its intellectual content. All authors had full access to all the data and take responsibility for the integrity of the data and accuracy of the analysis. EHO is the guarantor.

Funding This project is funded by the South Eastern Norway Regional Health Authority (grant number 2010003). http://www.helse-sorost.no/omoss/ english/Sider/page.aspx. The funders had no role in the study design, data collection and analysis, decision to publish, or preparation of the manuscript.

Competing interests None declared.

Ethics approval Our study was approved by the Regional Ethics Committee for Medical Research of South-East Norway (1.2009/1415).

Provenance and peer review Not commissioned; externally peer reviewed.

Data sharing statement No additional data are available.

Open Access This is an Open Access article distributed in accordance with the Creative Commons Attribution Non Commercial (CC BY-NC 4.0) license, which permits others to distribute, remix, adapt, build upon this work noncommercially, and license their derivative works on different terms, provided the original work is properly cited and the use is non-commercial. See: http:// creativecommons.org/licenses/by-nc/4.0/

\section{REFERENCES}

1. Schwartz A, Bergus G. Medical decision making: a physician's guide. New York: Cambridge University Press, 2008.

2. http://www.en.wikipedia.org/wiki/Decision-making (accessed 6 Dec 2015).

3. Merriam-webster's dictionary and thesaurus. Springfield, Massachusetts: Merriam-Webster Incorporated, 2014:273.

4. Feinstein AR. Clinical judgment. Huntington, NY: R.E. Krieger Pub. Co., 1967.

5. Dowie J, Elstein AS. Professional judgment: a reader in clinical decision making. New York: Cambridge University Press, 1988.

6. Wulff HR, Gøtzche PC. Rational diagnosis and treatment: evidence-based clinical decision-making. Malden, MA: Blackwell Science, 2000.

7. Chapman GB, Sonnenberg FA. Decision making in health care: theory, psychology, and applications. New York: Cambridge University Press, 2000.

8. Hunink MGM, Glasziou P, Siegel J, et al. Decision making in health and medicine: integrating evidence and values. New York: Cambridge University Press, 2001.
9. Gigerenzer G, Muir Gray JA, eds. Better doctors, better patients, better decisions: envisioning health care 2020. Cambridge, Massachusetts: MIT Press, 2013.

10. Sackett DL. Evidence-based medicine: how to practice and teach EBM. New York: Churchill Livingstone, 2000.

11. Haynes RB, Devereaux PJ, Guyatt GH. Clinical expertise in the era of evidence-based medicine and patient choice. ACP J Club 2002;136:A11-14.

12. Braddock $\mathrm{CH}$, Finn SD, Levinson W, et al. How doctors and patients discuss routine clinical decisions. Informed decision making in the outpatient setting. J Gen Intern Med 1997;12:339-45.

13. Deber RB. Physicians in health care management: 8 . The patient-physician partnership: decision making, problem solving and the desire to participate. CMAJ 1994;151:423-7.

14. Måseide $P$. The deep play of medicine: discursive and collaborative processing of evidence in medical problem solving. Commun Med 2006;3:43-54.

15. Norman G. Research in clinical reasoning: past history and current trends. Med Educ 2005;39:418-27.

16. Fossli Jensen B, Gulbrandsen P, Dahl FA, et al. Effectiveness of a short course in clinical communication skills for hospital doctors: results of a crossover randomized controlled trial (ISRCTN22153332). Patient Educ Couns 2011; 84:163-9.

17. Gulbrandsen $P$, Jensen BF. Post-recruitment confirmation of informed consent by SMS. J Med Ethics 2010;36:126-8.

18. Borkan J. Immersion crystallization. In: Crabtree BF, Miller WL, eds. Doing qualitative research. 2nd edn. Thousand Oaks, CA: Sage, 1999:179-94.

19. Weed LL. The problem oriented record as a basic tool in medical education, patient care and clinical research. Ann Clin Res 1971;3:131-4.

20. Ofstad EH, Frich JC, Schei E, et al. Temporal characteristics of decisions in hospital encounters: a threshold for shared decision making? A qualitative study. Patient Educ Couns 2014;97:216-22.

21. Addison RB. A grounded hermeneutic editing approach. In: Crabtree BF, Miller WL. Doing qualitative research. 2nd edn. Thousand Oaks, CA: Sage Publications, 1999:145-61.

22. Braddock $\mathrm{CH}$, Edwards $\mathrm{KA}$, Hasenberg NM, et al. Informed decision making in outpatient practice: time to get back to basics. JAMA 1999;282:2313-20.

23. Bradley EH, Curry LA, Devers KJ. Qualitative data analysis for health services research: developing taxonomy, themes, and theory. Health Serv Res 2007:42:1758-72.

24. Kuper A, Lingard L, Levinson W. Critically appraising qualitative research. BMJ 2008;337:a1035.

25. Crabtree BF, Miller WL. Using codes and code manuals, a template organizing style of interpretation. In: Crabtree BF, Miller WL. Doing qualitative research. 2nd edn. Thousand Oaks, CA: Sage Publications, 1999:163-77.

26. Krippendorff $\mathrm{KH}$. Content analysis: an introduction to its methodology. 3rd edn. Thousand Oaks: SAGE Publications, Inc 2013:221-32.

27. Clayman ML, Makoul G, Harper MM, et al. Development of a shared decision making coding system for analysis of patient-healthcare provider encounters. Patient Educ Couns 2012;88:367-72.

28. Saba GW, Wong ST, Schillinger D, et al. Shared decision making and the experience of partnership in primary care. Ann Fam Med 2006;4:54-62.

29. Hauer KE, Fernandez A, Teherani A, et al. Assessment of medical students' shared decision-making in standardized patient encounters. J Gen Intern Med 2011;26:367-72.

30. Ely JW, Osheroff JA, Ebell MH, et al. Analysis of questions asked by family doctors regarding patient care. BMJ 1999;319:358-61.

31. Del Fiol G, Workman TE, Gorman PN. Clinical questions raised by clinicians at the point of care: a systematic review. JAMA Intern Med 2014;174:710-8.

32. Zikmund-Fisher BJ, Couper MP, Singer E, et al. The DECISIONS study: a nationwide survey of United States adults regarding 9 common medical decisions. Med Decis Making 2010;30(5 Suppl):20S-34S.

33. Fowler FJ, Gerstein BS, Barry MJ. How patient centred are medical decisions?: results of a national survey. JAMA Intern Med 2013:173:1215-21.

34. Schuur JD, Carney DP, Lyn ET, et al. A top-five list for emergency medicine: a pilot project to improve the value of emergency care. JAMA Intern Med 2014;174:509-15.

35. Cook DA, Sorensen KJ, Wilkinson JM, et al. Barriers and decisions when answering clinical questions at the point of care: a grounded theory study. JAMA Intern Med 2013;173:1962-9. 